\title{
How Stephen Hawking Defied Amyotrophic Lateral Sclerosis for Five Decades
}

\author{
Chin-Lung Kuo, MD, PhD',2 \\ ${ }^{1}$ Institute of Brain Science, National Yang-Ming University School of Medicine, Taipei, Taiwan \\ 2Department of Otolaryngology-Head and Neck Surgery, Taoyuan Armed Forces General Hospital, Taoyuan, Taiwan
}

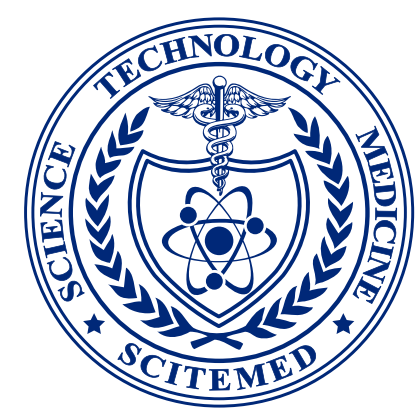

\begin{abstract}
Stephen Hawking died in Cambridge on March 14, 2018 at the age of 76. He has been described as one of the greatest scientific minds in history and the most popular scientific figure since Albert Einstein. He is also a symbol of human courage and persistence, having continued in his work for decades in spite of a debilitating disease that left him confined to a wheelchair. Hawking was diagnosed with amyotrophic lateral sclerosis in his early twenties. This rare disease leads to gradual decline of the brain's ability to control muscles. Doctors predicted that he would live for only a few years, but the advance of the disease was slower than expected, thereby allowing him to pursue an illustrious career articulating theories of the cosmos and bringing science to the forefront of popular culture.
\end{abstract}

S tephen Hawking amazed the scientific world with his theories on the nature of the cosmos; however, he also amazed neurologists by defying the odds in surviving for five decades after his diagnosis with amyotrophic lateral sclerosis (ALS) [1-4]. Most people diagnosed with ALS die within five years, and the average life expectancy is only 14 months.

Stephen Hawking developed the motor neuron disease ALS in his early 20s. At that time, he felt that he had been dealt an unfair hand. During his third year at Oxford, he found himself becoming increasingly clumsy and falling frequently [1]. While in Cambridge, his father took him to the family physician who sent him to the hospital for tests after his 21st birthday. Stephen Hawking told the British Medical Journal that this motor neuron disease has many potential causes, and that his ailment might be due to an inability to absorb vitamins [1].

After numerous tests, the doctors told him that his was an atypical case. Hawking came to realize that his condition would worsen and that doctors could do little more than prescribe vitamins. His condition eventually confined him to a wheel chair and by the late 1960s, he was experiencing difficulties writing. In the 1970s, he began to have trouble expressing himself verbally, and in 1985 he underwent a tracheotomy after which he never regained the ability to speak [1].

\section{Amyotrophic Lateral Sclerosis}

ALS accounts for $85 \%$ of cases of motor neuron disease [5]. ALS is a fatal, paralytic disorder resulting from a degeneration of motor neurons in the spinal cord and brain. Most cases are sporadic; however, approximately 5 to $10 \%$ are familial $[2,5]$.

Several potential mechanisms have been proposed to be associated with the pathogenesis of ALS including, glutamate-induced excitotoxicity, oxidative stress, protein aggregation, and mitochondrial dysfunction (Figure 1) [6]. Research into the molecular mechanisms behind the degeneration of motor neurons in ALS has revealed that the most common mutation occurs in the gene encoding the antioxidant enzyme superoxide dismutase 1 (SOD1). The SOD1 gene codes for copper/zinc ion-binding SOD [2]. Familial ALS is also associated with several other genes, including TARDBP encoding TAR DNA-binding protein 43 (TDP-43); FUS, coding for fusion in sarcoma; ANG, coding for angiogenin, ribonuclease, and the RNAase A family 5; OPTN, coding for optineurin; and C9orf72 [5,7-12]. Nonetheless, the roots of other forms of ALS have yet to elucidated. Despite extensive research into the genes identified as the cause of ALS, the actual pathogenic mechanism behind motor-neuron degeneration remains a mystery. Some cases of ALS are associated with dementia; however, the link between the two conditions remains unclear [13]. Progression of this neuromuscular disease affects the motor neurons in the brain and spinal cord that are responsible for transmitting signals to voluntary muscles in the body. ALS is characterized by gradual weakening due to the withering of muscle, causing difficulty speaking, swallowing, and eventually even breathing. ALS remains incurable, and no medication capable of halting or reversing the progressive loss of neurons has been developed. Nonetheless, the disease is not untreatable. ALS management has improved considerably over the past few decades [2,14-21].

\section{How Hawking Survived 5 Decades with ALS}

ALS predominantly affects people aged $50-60$ years, and only $5 \%$ of patients experience onset before the age of 30 years $[1,2,5]$. The prognosis for younger patients is far better than for those diagnosed in middle or old age [2,5]. The fact that Hawking lived with this terminal disease for so long was unprecedented. His ALS progressed more slowly than expected and eventually burnt itself out $[1,3]$. His indomitable will and the care he received no doubt also contributed to his ability to survive for as long as he did.

\section{Determination and Success}

The onslaught of the disease overtook most of his muscles, which forced him to communicate using a voice synthesizer. For the remainder of his life, the only control he had over his body was in his eyes and his fingers with which he controlled his wheelchair. Despite being confined to a wheelchair, he lived life to the full, both professionally and personally. He never allowed his physical condition to interfere with the way he lived his life. On his 60th birthday, he took a hot-air balloon flight and at the age of 65 , he took part in a zero-gravity flight. His attendance at scientific meetings and conferences brought him to every continent, including Antarctica. He married twice and is survived by three children. He never lost his sense of humor or zest for life. He enjoyed racing his wheelchair around Cambridge where he lived, and even had an accident that resulted in a broken bone.

He appeared in cameo performances in the popular TV series Star Trek: The Next Generation, the comedy series The Big Bang Theory, and was even portrayed in The Simpsons. A six-part television series called Stephen Hawking's Universe explained concepts such as the Big Bang theory, dark matter and black holes as well as the origin of the universe [22]. His life story was told in the popular movie, The Theory of Everything (2014). 


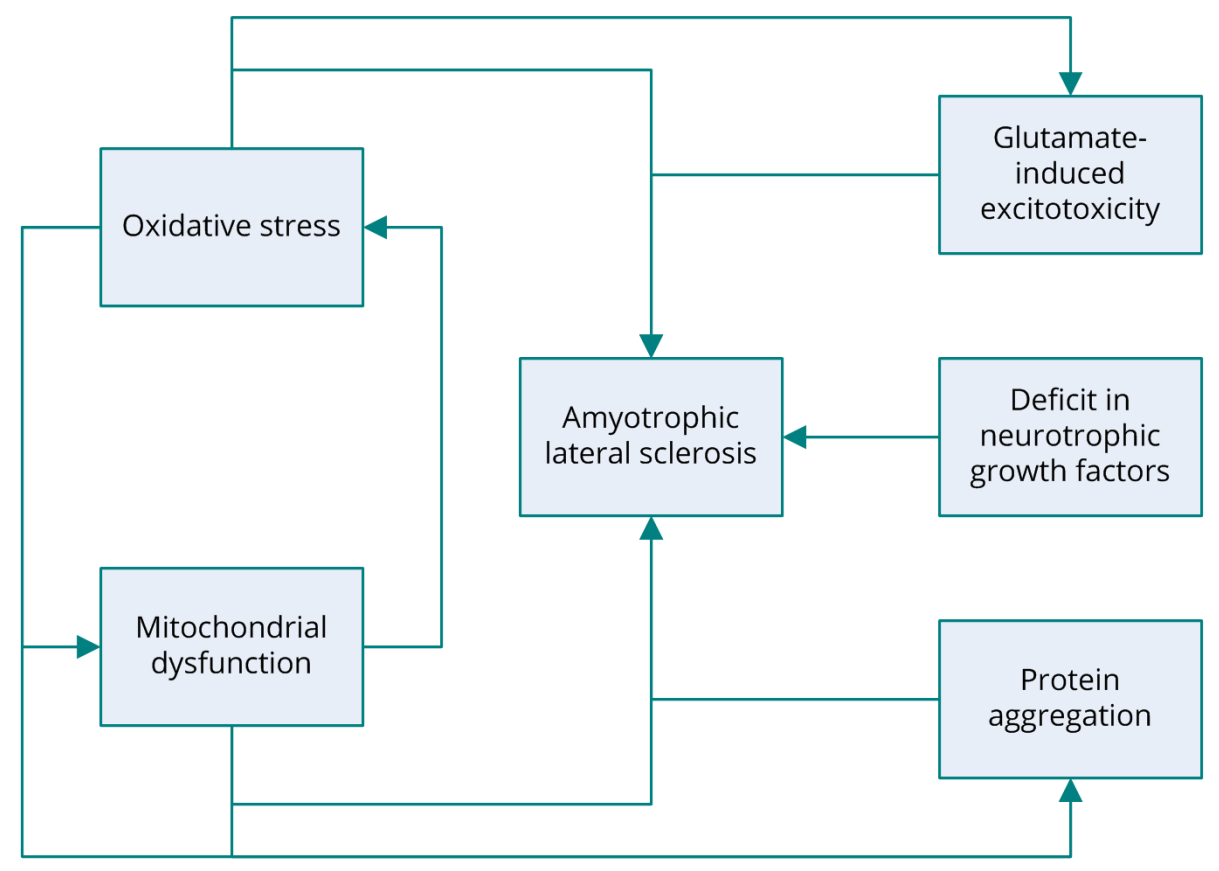

Figure 1. Several pathogenic mechanisms of amyotrophic lateral sclerosis have been proposed, including glutamate-induced excitotoxicity, oxidative stress, protein aggregation, mitochondrial dysfunction, and deficit in neurotrophic growth factors. ALS, amyotrophic lateral sclerosis.

Stephen Hawking addressed many of the most basic questions about the universe, such as why we are here and where we came from [23]. That quest led him to a landmark in the advancement of science. He made some of the most important advances in our understanding of black holes, a concept derived from Einstein's General Theory of Relativity. His work with Roger Penrose revealed that the universe has a beginning and an end [24]. He theorized that space and time began at the Big Bang and would end ultimately in the evaporation of black holes.

Black holes are regions in the cosmos with gravitational forces that are so strong that not even radiation or light can escape. He postulated what would happen to matter sucked into a black hole, and his work represents a turning point in modern physics. No researcher before Hawking had applied quantum theory to the study of black holes, due to the fact that the scale of spacetime is infinitely large compared to the Planck length of $10^{-33} \mathrm{~cm}$. Hawking's linking of gravity and quantum mechanics revealed a universe beyond the imagination of most scientists at the time.

His proposal that matter could be erased from the universe contradicted conventional thinking and the most basic tenets of quantum theory. He also made important progress in linking General Relativity and Quantum Mechanics to the Laws of Thermodynamics. His calculations showed that black holes would eventually spew out radiation, explode, and disappear. A black hole is no longer black when it explodes [25]. Hawking expressed a desire that the radiation leaked from black holes, known as Hawking radiation, would be inscribed on his tombstone.

Hawking Stephen had a tremendous talent for explaining difficult theories using non-technical language. His book A Brief History of Time: From the Big Bang to Black Holes (1988) became a best-seller and made him famous outside the scientific community. That book brought to life for people in all walks of life the mysteries of the Big Bang, the expansion of the universe, black holes, and other cosmological phenomena [26].

Stephen Hawking won numerous honors during his lifetime. He was inducted into the Royal Society in 1974. He was the recipient of the Albert Einstein Award in 1978. Queen Elizabeth II bestowed on him the highest distinction when she made him a Companion of Honor in 1989. The fact that he was denied a Nobel prize is due only to the speculative nature of his work. Nonetheless, recent work conducted by the Laser Interferometer Gravitational-wave Observatory (LIGO) in the US may well provide proof of his theories. In February 2016, LIGO detected gravitational waves generated from a black hole merger. It was the first ever reading of this kind and may prove Hawking's theory about the fate of black holes. Later in the year, LIGO reported a second detection of gravitational waves caused by colliding black holes [27]. His work has provided important new directions for the advancement of scientific thought.

Stephen Hawking will continue to be an inspiration to millions of people. Even in the face of extreme adversity, he lived a full life and made important contributions to the advancement of humankind.

\section{ARTICLE INFORMATION}

*Correspondence: Chin-Lung Kuo, MD, PhD, Department of Otolaryngology-Head and Neck Surgery, Taoyuan Armed Forces General Hospital, Taoyuan, Taiwan. E-mail: drkuochinlung@gmail.com

Received: Mar. 02, 2019; Accepted: Mar. 07, 2019; Published: Mar. 09, 2019

DOI: $10.24983 /$ scitemed.cmt.2019.00105

Ethics Approval and Consent to Participate: The study is in accordance with the ethical standards of the 1964 Helsinki declaration and its later amendments or comparable ethical standards.

Funding: This study was sponsored by grants from Medical Affairs Bureau Ministry of National Defense (MAB-107-099) and Taoyuan Armed Forces General Hospital (AFTYGH-10734 and AFTYGH-10830).

Conflict of Interest: The authors report no financial or other conflict of interest relevant to this article, which is the intellectual property of the authors.

Copyright $@ 2019$ The Author. This is an open-access article distributed under the terms of the Creative Commons Attribution 4.0 International License (CC-BY). 


\section{REFERENCES}

1. Dobson R. An exceptional man. BMJ 2002;324(7352):1478.

2. Zarei S, Carr K, Reiley L, et al. A comprehensive review of amyotrophic lateral sclerosis. Surg Neurol Int 2015;6:171.

3. Winter RO, Birnberg BA. Tuesdays with morrie versus stephen hawking: Living or dying with als. Fam Med 2003;35(9):629-631.

4. Kayano S, Sakuraba M, Miyamoto $S$, et al. Comparison of pedicled and free anterolateral thigh flaps for reconstruction of complex defects of the abdominal wall: Review of 20 consecutive cases. J Plast Reconstr Aesthet Surg 2012;65(11):1525-1529.

5. Gouveia LO, de Carvalho M. Young-onset sporadic amyotrophic lateral sclerosis: A distinct nosological entity? Amyotroph Lateral Scler 2007;8(6):323-327.

6. Musaro A. State of the art and the dark side of amyotrophic lateral sclerosis. World J Biol Chem 2010;1(5):62-68.

7. Blair IP, Williams KL, Warraich ST, et al. Fus mutations in amyotrophic lateral sclerosis: Clinical, pathological, neurophysiological and genetic analysis. J Neurol Neurosurg Psychiatry 2010;81(6):639-645.

8. Chio A, Borghero G, Pugliatti M, et al. Large proportion of amyotrophic latera sclerosis cases in sardinia due to a single founder mutation of the tardbp gene. Arch Neurol 2011;68(5):594-598.

9. Corrado L, Del Bo R, Castellotti B, et al. Mutations of fus gene in sporadic amyotrophic lateral sclerosis. J Med Genet 2010;47(3):190-194.

10. Gijselinck I, Van Langenhove T, van der Zee J, et al. A c9orf72 promoter repeat expansion in a flanders-belgian cohort with disorders of the frontotemporal lobar degeneration-amyotrophic lateral sclerosis spectrum: A gene identification study. Lancet Neurol 2012;11(1):54-65.

11. Kwiatkowski TJ, Jr., Bosco DA, Leclerc AL, et al. Mutations in the fus/tls gene on chromosome 16 cause familial amyotrophic lateral sclerosis. Science 2009;323(5918):1205-1208.

12. Majounie $E$, Renton $A E$, Mok K, et al. Frequency of the $c 9$ orf 72 hexanucleotide repeat expansion in patients with amyotrophic lateral sclerosis and frontotemporal dementia: A cross-sectional study. Lancet Neurol 2012;11(4):323-330.

13. Deng $\mathrm{HX}$, Chen $\mathrm{W}$, Hong ST, et al. Mutations in ubqln2 cause dominant $\mathrm{x}$-linked juvenile and adult-onset als and als/dementia. Nature 2011;477(7363):211-215.
14. Chancellor AM, Slattery JM, Fraser H, Swingler RJ, Holloway SM, Warlow CP. The prognosis of adult-onset motor neuron disease: A prospective study based on the scottish motor neuron disease register. J Neurol 1993;240(6):339-346.

15. Leigh PN, Abrahams S, Al-Chalabi A, et al. The management of motor neurone disease. J Neurol Neurosurg Psychiatry 2003;74 Suppl 4:iv32-iv47.

16. Millul A, Beghi E, Logroscino G, Micheli A, Vitelli E, Zardi A. Survival of patients with amyotrophic lateral sclerosis in a population-based registry. Neuroepidemiology 2005;25(3):114-119.

17. Orrell RW. Motor neuron disease: Systematic reviews of treatment for als and sma. Br Med Bull 2010;93:145-159.

18. Radunovic A, Mitsumoto H, Leigh PN. Clinical care of patients with amyotrophic lateral sclerosis. Lancet Neurol 2007;6(10):913-925.

19. Simmons Z. Management strategies for patients with amyotrophic lateral sclerosis from diagnosis through death. Neurologist 2005;11(5):257-270.

20. Van den Berg JP, Kalmijn S, Lindeman E, et al. Multidisciplinary als care improves quality of life in patients with als. Neurology 2005;65(8):1264-1267.

21. Wijesekera LC, Leigh PN. Amyotrophic lateral sclerosis. Orphanet J Rare Dis 2009;4:3.

22. Friji MT, Suri MP, Shankhdhar VK, Ahmad QG, Yadav PS. Pedicled anterolateral thigh flap: A versatile flap for difficult regional soft tissue reconstruction. Ann Plast Surg 2010;64(4):458-461.

23. Hofer SO. A pedicled anterolateral thigh flap for abdominal reconstruction after previous degloving injury of the donor site: Revascularisation of the donor site. Scand J Plast Reconstr Surg Hand Surg 2007;41(4):203-206.

24. Jang J, Jeong SH, Han SK, Kim WK. Reconstruction of extensive abdominal wall defect using an eccentric perforator-based pedicled anterolateral thigh flap: A case report. Microsurgery 2013;33(6):482-486.

25. Matsumine $\mathrm{H}$, Takeuchi $\mathrm{M}$. Reconstruction for planned ventral hernia after surgery for generalised peritonitis: De-epithelialisation of split-thickness skin graft and transplantation of pedicled anterolateral thigh flap. J Plast Reconstr Aesthet Surg 2013;66(2):290-291.

26. Hawking S. A Brief History of Time. New York: Bantam Books; 1988

27. Nthumba P, Barasa J, Cavadas PC, Landin L. Pedicled fasciocutaneous anterolateral thigh flap for the reconstruction of a large postoncologic abdominal wall resection defect: A case report. Ann Plast Surg 2012;68(2):188-189. 